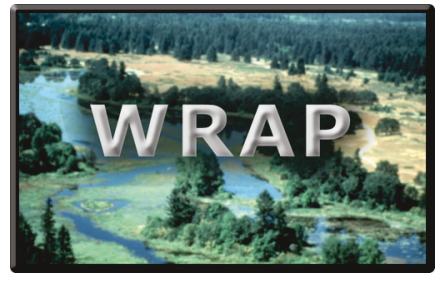

\title{
Unmanned Aircraft Systems (UAS) and Satellite Imagery Collections in a Coastal Intermediate Marsh to Determine the Land- Water Interface, Vegetation Types, and Normalized Difference Vegetation Index (NDVI) Values
}

\author{
by Whitney P. Broussard III, Glenn M. Suir, \\ and Jenneke M. Visser
}

PURPOSE: The purpose of this project was to evaluate and compare methodologies for using remotely sensed hyperspatial imagery from both Unmanned Aircraft Systems (UAS) and nextgeneration satellite technology to calculate species composition and ecosystem service metrics in a coastal intermediate marsh. Such methods would be important steps towards comprehensive monitoring of wetland landscapes and would provide useful metrics to study wetland condition and response to ecosystem restoration and disturbance events.

BACKGROUND: Plant species composition, cover, density, and biomass are structural components of coastal marshes that are commonly used to quantify vegetative characteristics and often serve as indicators of wetland condition (Chamberlain and Ingram 2012; Cretini et al. 2012). Historically, regional and coastwide surveys to map coastal vegetation have consisted of laborious traversing of wetland landscapes, including time consuming and subjective ocular estimates of species type and cover (O’Neil 1949; Chabreck and Linscombe 1978; Sasser et al. 2014). Although recent surveys, like those in coastal Louisiana, enlist the use of helicopters for transport between, and hovering over, sampling sites, they continue to rely on ocular estimates of dominant species and abundance (i.e., Braun-Blanquet cover scale), they are costly, and are typically reproduced approximately every ten years. Rapid species classification (even of dominant plants) using remotely sensed data would provide many advantages over traditional field techniques.

A primary monitoring program for coastal vegetation in Louisiana is the Coastwide Reference Monitoring System (CRMS). CRMS sites are located throughout the Louisiana coastal zone and serve as the ambient coastal wetland monitoring network for the region (Steyer 2010). CRMS sites, which were used as reference data sets for this study, consist of 200 meters (m) x 200 m on-theground sample stations where species cover, plant height, and vegetation community type are measured and monitored during peak biomass at various intervals ranging from seasonal to every $2-$ 3 years (Folse et al. 2014). Additionally, the land-water interface around $1 \mathrm{~km}^{2}$ of each CRMS site is mapped every three years using traditional aerial photography and satellite imagery (USGS and LACPRA 2018).

Remotely sensed data provide spatial and temporal perspectives on ecological phenomena that would otherwise be difficult to study (Anderson and Gaston 2013). Moreover, UASs are emerging as flexible platforms that in many cases overcome previous constraints (i.e., cost; atmospheric contamination; and spatial, spectral, and temporal limitations), and therefore, have the potential to supplement or replace traditional in situ and remotely collected data (Whitehead and Hugenholtz 
2014). UAS technology has expanded in recent years for various survey and mapping applications. In the late 1970s, Przybilla and Wester-Ebbinghaus (1979) first used a fixed wing remotely controlled aircraft in photogrammetry experiments. In 2004, Eisenbeiss, Lambers, and Sauerbier (2005) were the first to create a high-resolution digital terrain model using a commercial low-cost model helicopter with semi-automated navigation. UAS technology has developed quickly since the turn of the century and has witnessed unprecedented developments in computing, communications, navigation, control, and optics (Pereira et al. 2009).

Space-borne systems provide many advantages for environmental applications (i.e., wildlife and critical habitat surveys, forest structure and sustainable management, land surface and land use change and impacts, and monitoring hydrology and riverine ecosystems), especially those that require collection and assessments over large areal extents. While some systems lack flexibility (i.e., acquisition, cost, and resolution), some high resolution satellite image sources are available for acquisition at no cost to the U.S. Army Corps of Engineers (USACE) through the National Geospatial-Intelligence Agency's (NGA's) EnhancedView contract. All EnhancedView acquisitions (archived and new data collections), are coordinated through the Army Geospatial Center's (AGC's) Imagery Office (AIO). The data holdings directly support engineering, planning, and response requirements of USACE activities and allow end-users direct access to commercial imagery products, available in various formats and online repositories.

Comparing UAS- and satellite-based methods. Comparing UAS and satellite data analysis is not straightforward. Each method has a niche and a best-fit for project application. There are various trade-offs to consider such as cost, area covered, resolution, and the potential for high temporal sampling, etc. Satellite deployment, maintenance, and data acquisition, for example, can be costly (Klemas 2013) as compared with UAS technology on smaller areas of interest. However, satellites can cover and map larger areas of interest at a lesser cost because of economies of scale. Global positioning satellite (GPS)-guided UAS have the capacity to obtain very high spatial resolution (1$10 \mathrm{~cm}$ ) imagery of specific landscape features with revisit times determined by the operator as opposed to fixed satellite revisit times (Lechner et al. 2012).

For coastal wetland monitoring in Louisiana, there are several examples of remote sensing data types, at various spatial scales, that can fill in the data gaps between the helicopter coastwide survey and the CRMS network stations. These include Landsat satellite imagery (30 m), WorldView (WV) satellite imagery $(30-50 \mathrm{~cm})$, traditional aircraft captured aerial photography $(30 \mathrm{~cm}-1 \mathrm{~m})$, and UAS captured aerial photography $(2-10 \mathrm{~cm})$. Additionally, the ability to remotely capture high spatial and temporal data and then classify these data sets by dominant species, assess plant health using the Normalized Difference Vegetation Index (NDVI), and calculate elevation as Digital Elevation Models (DEM) or Digital Surface Models (DSM), would be an improvement over current methods. The ability to scale up these estimates from the site-specific scale to the landscape or regional scale is particularly appealing for restoration program managers.

Few studies have evaluated the use of UASs and next-generation satellite data to classify, monitor, and assess wetland vegetation and condition. The primary objective of this pilot study was to investigate the effectiveness of high-resolution multispectral imagery (UAS and satellite) in classifying species composition and quantifying ecosystem services (i.e., plant productivity and the land-water interface), in an intermediate coastal marsh environment. Specifically, the goals of this study were to capture air- 
and space-borne imagery to create 1) georeferenced orthomosaic images $(2 \mathrm{~cm}$ for UAS and $30-50 \mathrm{~cm}$ for pansharpened WV imagery), 2) NDVI thematic maps, 3) classified land and water interface, 4) classification of dominant species, and 5) Digital Surface Models. With this information, the authors hope to compare methodologies that can capitalize on recent developments in UAS hyperspatial and WV high resolution imagery, and provide meaningful metrics that will assist resource managers in the monitoring and quantification of wetland ecosystems.

\section{METHODS}

Study site. This pilot study consisted of collecting, processing, and evaluating hyperspatial airborne and high spatial resolution space-borne imagery in an intermediate marsh environment $(0.5$ to 5 practical salinity $\left.\left[S_{\mathrm{P}}\right]\right)$ in coastal Louisiana. The Terrebonne project site is a degraded marsh dominated by Spartina patens (marshhay cordgrass), approximately four kilometers $(\mathrm{km})$ south of Houma, Louisiana (Figure 1). The site is 0.725 square kilometers $\left(\mathrm{km}^{2}\right)$, and overlaps a portion of the CRMS station 0392, which was used as a vegetation (i.e., species composition and cover) reference data set (Figure 1).

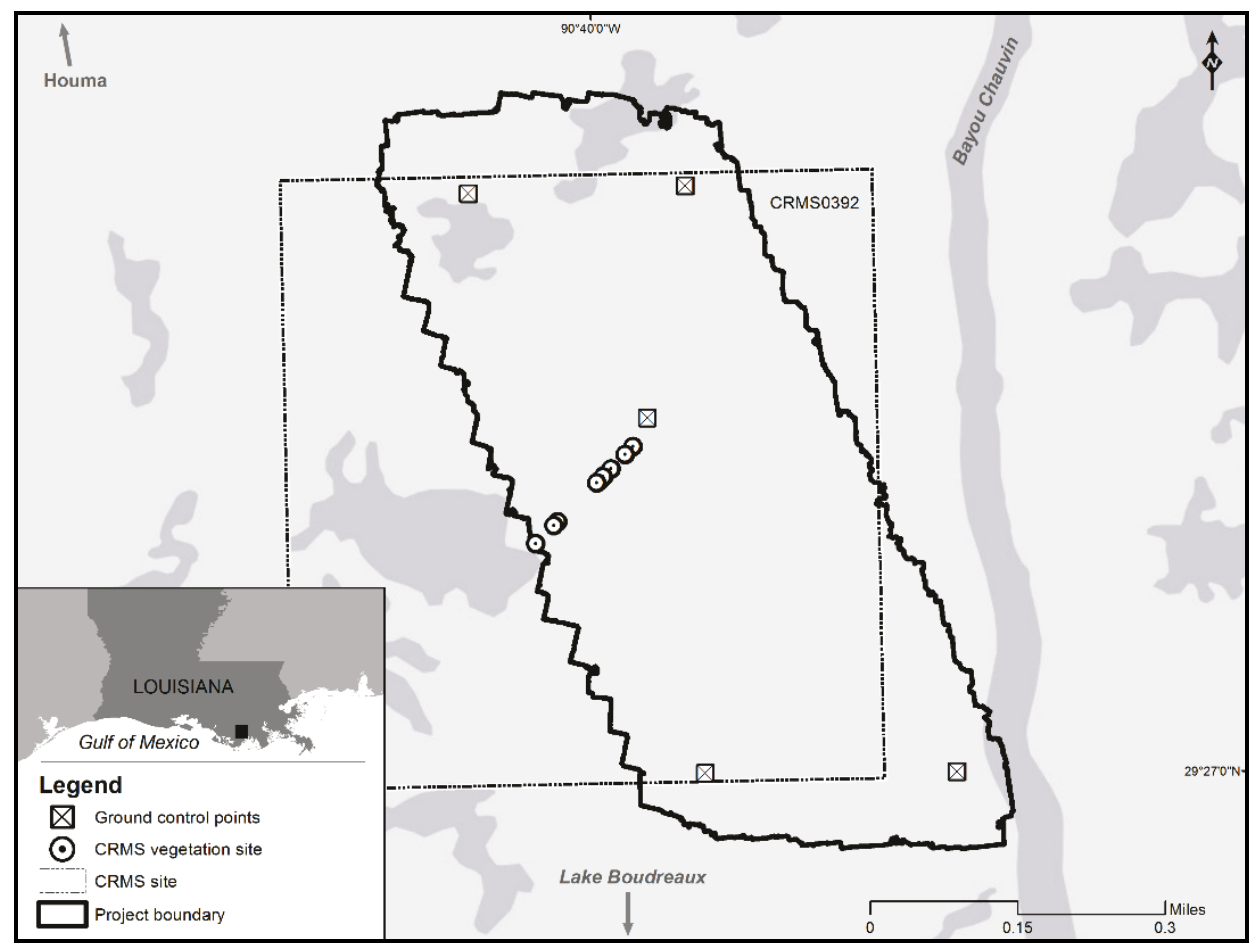

Figure 1. Project site location in coastal Terrebonne Parish, Louisiana.

CRMS site 0392 was chosen with permission from the state governing agency, the Louisiana Coastal Protection and Restoration Authority (LACPRA), and the private landowner. Even though the site was in Class $\mathrm{G}$ airspace (completely uncontrolled), the pilot in command coordinated with the Houma-Terrebonne Airport (HUM) because the site was under the Class E airspace (completely controlled) surrounding HUM. The fieldwork for this project was conducted August 29 and 30, 2016. All flight operations were compliant with the Federal Aviation Authority (FAA) Part 107 ruling. 
UAS image acquisition. A Trimble UX5 Aerial Rover (Figure 2) was used to collect UAS aerial imagery of the study site. Payload sensors included the Sony a5100 with a red-green-blue (RGB) sensor and a Sony NEX-5r modified to capture the near-infrared (NIR) spectrum using a B+W 040 (orange) filter to suppress green, blue, and violet colors while allowing yellow, orange, red, and near-infrared to pass through more easily. Ground control point (GCP) photo targets were evenly placed throughout the project area (Figures 1 and 2). The targets were vinyl sheets $(60 \mathrm{~cm} \times 60 \mathrm{~cm})$ with an iron cross pattern. The targets were fixed atop wooden stakes that were driven into the marsh and elevated so that the targets were visible over the marsh grass (Figure 2). A center stake was driven in the middle of the target to create a tent effect and fix the location of the center of the target at the top of this tent-like structure. The center point was then surveyed in using high accuracy GPS equipment (Figure 2; horizontal accuracy $=1 \mathrm{~cm}$, vertical accuracy $=2 \mathrm{~cm}$ ).

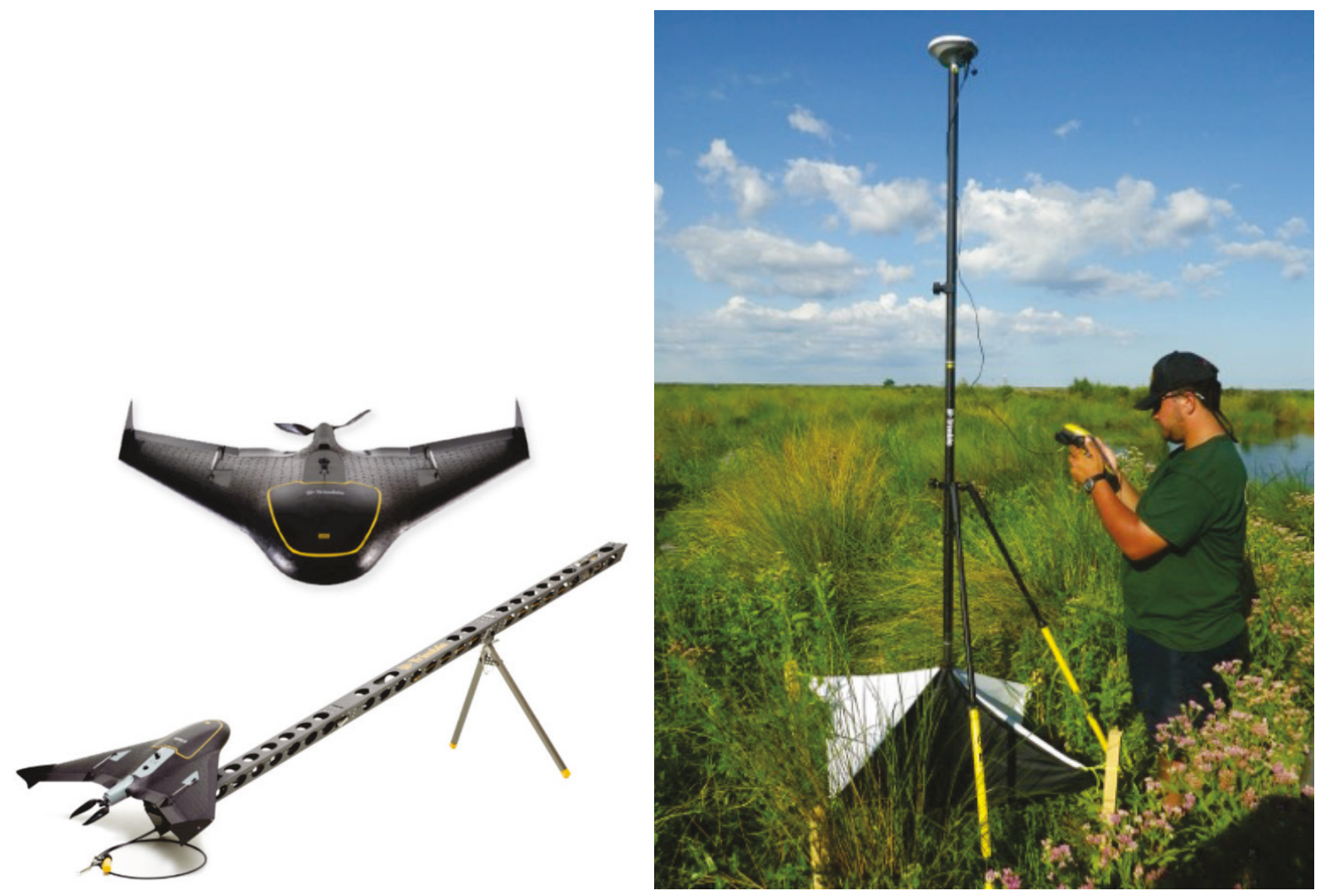

Figure 2. UX5 aerial rover (left) and surveyed ground control point (right).

UAS image post-processing. Trimble UAS Master Inpho Software was the photogrammetric software used to process the UAS imagery and generate orthomosaic and Digital Surface Model raster data sets. Over 2000 images are collected in two flights over the project area. Each image has an approximate latitude, longitude, altitude, roll, pitch, and yaw value associated with it. These initial approximations of the image's external orientation were used by the software to extract tie point locations, (i.e., those locations that could be identified in multiple photos). The precise location of the GCPs were measured in all available images. Each GCP was measured (located) within each available picture to refine the initial orientation and to tightly georeference the orthomosaics to a datum. The root mean square error (RMSE) of the final orthomosaics were $2.40 \mathrm{~cm}$, and $2.42 \mathrm{~cm}$, for the horizontal and vertical control, respectively. The $95 \%$ confidence level for the horizontal and 
vertical control was $4.83 \mathrm{~cm}$ and $4.74 \mathrm{~cm}$, respectively. The ground sample distance was as low as $2.6 \mathrm{~cm}$ for the orthomosaic and $7.2 \mathrm{~cm}$ for the digital surface model.

Satellite image acquisition. The WorldView-2 (WV2 - $46 \mathrm{~cm}$ panchromatic and $185 \mathrm{~cm}$ multispectral, launched 2009) and WorldView-3 (WV3 $-31 \mathrm{~cm}$ panchromatic and $124 \mathrm{~cm}$ multispectral, launched 2014) sensors are the most spectrally diverse commercial satellites available to date. These sensors, which collect eight multispectral bands (coastal, yellow, blue, green, red, red edge, near-infrared 1, and near-infrared 2), were tasked to collect multispectral and stereo imagery near the same time as the UAS collections. The multispectral and stereo data were collected on 30 August 2016 and 21 October 2016, respectively, and acquired using the DigitalGlobe Enhanced Viewer Web Hosting Service. The Environment for Visualizing Images (ENVI) version 5.4.1 was used to perform radiometric, atmospheric, and geometric corrections on all satellite imagery (ITT Visual Information Solutions Inc. 2009).

Image analysis. The goal of the image analysis in this study was the classification of marsh grass versus open water, the identification of dominant plant species, and the development of NDVI surface models using multispectral UAS and satellite imagery. The first step in the analysis was to classify objects as either land or water and then to classify land objects into one of three of the following vegetation categories: 1) Grass, Spartina patens, 2) Reed, Phragmites australis, and 3) Other, a mix of Bacopa spp., Plucheas spp., Iva spp., and Baccharis spp.

Recent studies have used object-based image analysis (OBIA) classification methods to analyze UAS imagery (e.g., Laliberte and Rango 2009; Laliberte and Rango 2011). For the UAS imagery, Trimble eCognition Developer software and an OBIA workflow was used to delineate the hyperspatial imagery into objects based on similar spectral values, texture, and size, including the context of other neighboring objects. Based on the characteristics of objects that shared a common target classification, a rule set was then developed to methodically classify objects into one of the three target classes.

For the satellite-based image classifications, standard pixel-based methods were used to produce NDVI, land and water, and vegetation thematic maps. Details about each classification scheme, and related tests of performance (i.e., kappa coefficient and overall accuracy), are provided below.

Normalized Difference Vegetative Index (NDVI). The NDVI has well established correlations to photosynthetic activity, aboveground biomass, and leaf area index, and is therefore a primary measure of condition, function, recovery, and sustainability (Tucker 1979; Carle 2013). It is often used to estimate above-ground biomass, primary productivity and wetland species distributions, to assess impacts from anthropogenic activities and episodic events, and evaluate marsh collapse thresholds (An et al. 2013; Bianchette et al. 2009; Couvillion and Beck 2013; Klemas 2013; Steyer et al. 2013). NDVI assessments were performed using the air- and space-borne imagery and the standard equation (Rouse et al. 1974)

$$
\mathrm{NDVI}=\frac{N I R-R e d}{N I R+R e d}
$$

This equation utilizes a band ratio of imagery between a NIR and red band to measure an ecosystem's ability to capture solar energy and convert it to organic carbon or biomass (An et al. 
2013). NDVI values less than zero $(<0)$ are typical of non-vegetation features (e.g., water, cloud, impervious surfaces) (Reif et al. 2011; Carle 2013), so those were excluded from the NDVI assessments. An NDVI surface model was developed for both the UAS and satellite imagery data sets by calculating the index ratio by objects (UAS imagery) and pixel (satellite imagery).

Land-water. The ratio and interface of land and water are some of the more important features and metrics of wetland landscapes. Therefore, this study utilized land-water classification methodologies to compare air- and space-borne products.

The reflectance values of the near infrared spectrum, coupled with the hyperspatial resolution of the UAS imagery, provide for easier identification and separation of water objects. Because each pixel represented only $2.6 \mathrm{~cm}$ on the ground, there are fewer instances of spectral mixing, as most pixels are either land or water. Using a simple threshold level, those objects with a mean near-infrared reflectance value less than 90 were classified as water (because water absorbs near infrared wavelengths).

The satellite-based methodology for developing the land-water interface was a variant of the standard procedures used for CRMS land-water classifications (Folse et al. 2014). This classification scheme consisted of the modified Normalized Difference Water Index (mNDWI), the NDVI, and an ISODATA unsupervised classification. The mNDWI and NDVI have been shown to be adept at separating land-water features. The traditional NDWI normalizes a blue band against a NIR band, to identify water features. For WorldView data, the coastal and NIR2 bands provide greater spectral separation, therefore, they are used in the mNDWI to provide a more discrete threshold for detecting water areas (Wolf 2010). This index is described by the equation

$$
\text { mNDWI }=\frac{\text { Coastal }-N I R 2}{\text { Coastal }+ \text { NIR2 }}
$$

The mNDWI and NDVI data were used in conjunction with the unsupervised classification (30 max iterations, 0.99 convergence threshold, and 50 classes) and an accuracy assessment to generate WVderived land-water data. The mNDWI was also used to create a water mask that was used to exclude all non-vegetated features from other metric assessments.

Species classification. Identification of dominant vegetation species in UAS imagery used OBIA algorithms that focused primarily on height, texture, and greenness. Because the common reed, Phragmites australis, is a tall, clumping species, this Reed class was primarily identified by height (i.e., objects that were taller than their surrounding objects). The Other class was primarily identified by greenness because this class of plants were generally greener than the surrounding grasses. After classifying both the Reed and Other classes, the remaining objects belonging to the larger Land class were then classified as Grass.

For species classification using WV imagery, the Maximum Likelihood Classifier (MLC) in ENVI 5.4.1 was used to assign each pixel to a dominant species or land-cover class. The MLC is a parametric classifier that relies on statistical distributions of reflectance values, these are defined by training data for each class (Carle 2013). The CRMS vegetation data and the higher resolution UAS imagery were used to establish training and accuracy Regions of Interest (ROI) for dominant species and land-cover classes. 
Elevation. Rapid and accurate estimations of wetland vegetation height is useful for assessing wetland biomass, condition, and change (Luo et al. 2015). However, collecting elevation data in remote and densely vegetated wetlands can be difficult. The Inpho module of the UAS Master software suite includes a point cloud creation tool that uses photogrammetric techniques to calculate a $z$ elevation value for each $x, y$ coordinate. The final density of the point cloud and subsequent Digital Surface Model were defined as twice the Ground Sample Distance of the original resolution of the collected imagery, in this case $7.2 \mathrm{~cm}$.

Photogrammetric software also allows for feature and elevation extraction from satellite images that are acquired at optimal angles (stereo imagery). The DEM Extraction tool in ENVI 5.4.1 was used to create a DSM from WV-3 stereo imagery that was collected on 21 October 2016. The stereo pairs were used to create epipolar images which were image matched and geocoded using ground control points (ENVI 2009). An initial relative DEM was converted to an absolute DSM using 2015 reference first return Light Detection And Ranging (LiDAR) data (USGS 2016).

Landscape metrics. Landscape ecology is based on the premise that there are strong correlations between landscape pattern (configuration) and ecosystem function (Gustafson 1998). Recent studies have shown linkages between wetland loss, disturbance events, and wetland landscape configuration (Liu and Cameron 2001, Suir et al. 2013, Couvillion et al. 2016). A number of landscape metrics (i.e., total class area, percentage of landscape, number of patches, patch density, edge density, and aggregation index) were selected after careful consideration of previous landscape fragmentation and configuration studies. Though these measures represent general structure in wetland landscapes, the aggregation index (AI) has evolved as a primary metric for linking structure to ecosystem function. This index, which is defined as the frequency with which different pairs of patch types (including like adjacencies between the same patch type) appear side-by-side (McGarigal 2015), was used to assess landscape configuration between the UAS and WorldView imagery. The landscape aggregation index $\left(A I_{L}\right)$ is derived as

$$
\mathrm{AI}_{\mathrm{L}}=\left[\sum_{\mathrm{i}=1}^{\mathrm{n}}\left(\frac{\mathrm{e}_{\mathrm{i}, \mathrm{i}}}{\max \__{-} \mathrm{e}_{\mathrm{i}, \mathrm{i}}}\right) \mathrm{P}_{\mathrm{i}},\right](100),
$$

where $e_{i, i}$ is the number of like adjacencies between pixels of patch type $i$ (class), max $e_{i, i}$ is the maximum number of like adjacencies between pixels of patch type $i$, and $P_{i}$ is the proportion of landscape comprised of patch type $i$ (He et al. 2000; McGarigal 2015). The FRAGSTATS landscape pattern analysis software was used to compute landscape metrics on the final land-water classified data sets derived from the UAS and WV sensors.

\section{RESULTS AND DISCUSSION}

Orthomosaic images. This project demonstrated the ability to process both UAS $(2.6 \mathrm{~cm}$ pixel resolution) and WorldView-3 pansharped imagery (31 cm pixel resolution) for coastal wetlands monitoring purposes. UAS data can capture RGB and NIR data similar to traditional aerial photography and produce similar cartographic products at high resolutions (Figures 3). Satellitebased imagery can recreate the RGB data sets with much larger footprints, but lacks the traditional look and feel of aerial products (Figures 3). 

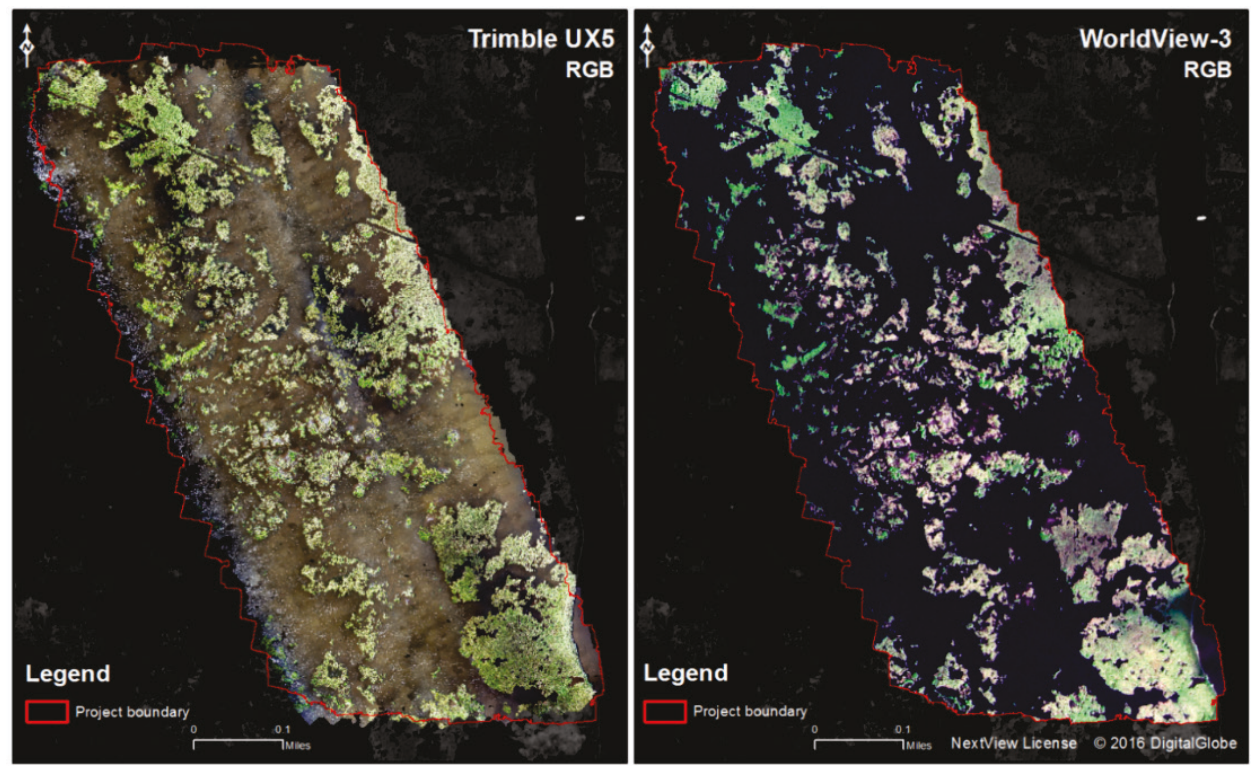

Figure 3. UAS red-green-blue (left) and pansharpened natural color (right), both collected on 30 August 2016.

Normalized difference vegetative index (NDVI) assessments. Both workflows presented here could satisfactorily derive an NDVI surface of the project area (Figure 4). The NDVI values ranged from zero (0), represented by the color red, to one (1), represented by the color green. The mean NDVI, for all vegetation pixels (NDVI >0), was 0.254 and 0.464 for the UAS and WorldView images, respectively. When compared to NDVI values from the literature, these values appear to be lower (UAS) and higher (WV) than the typical range $(\sim 0.36-0.4)$ for intermediate marsh in the Terrebonne basin. Table 1 consists of error summary statistics and accuracy statistics comparing the UAS and WV-derived NDVI data. The mean absolute forecast error (MAE) and RMSE between these data are relatively large, this is concerning since small changes or differences in NDVI values have been correlated to significant differences in biomass. One explanation for the lower than expected values of NDVI from the UAS data set is that the modified Sony NEX-5 camera was not designed and built to capture NIR data. More recent advancements in vegetation monitoring with UAS technology have introduced NIR-specific and multispectral sensors with ambient light corrections that more precisely reproduce true reflectance values. This is especially important when comparing multi-temporal data sets. For example, modified cameras are appropriately positioned to compare vegetation indices at one fixed moment in time whereas calibrated multispectral specific sensors are able to compare data sets captured annually or seasonally. More intensive evaluations of NDVI estimates using higher resolution sensors is necessary for future applications. 

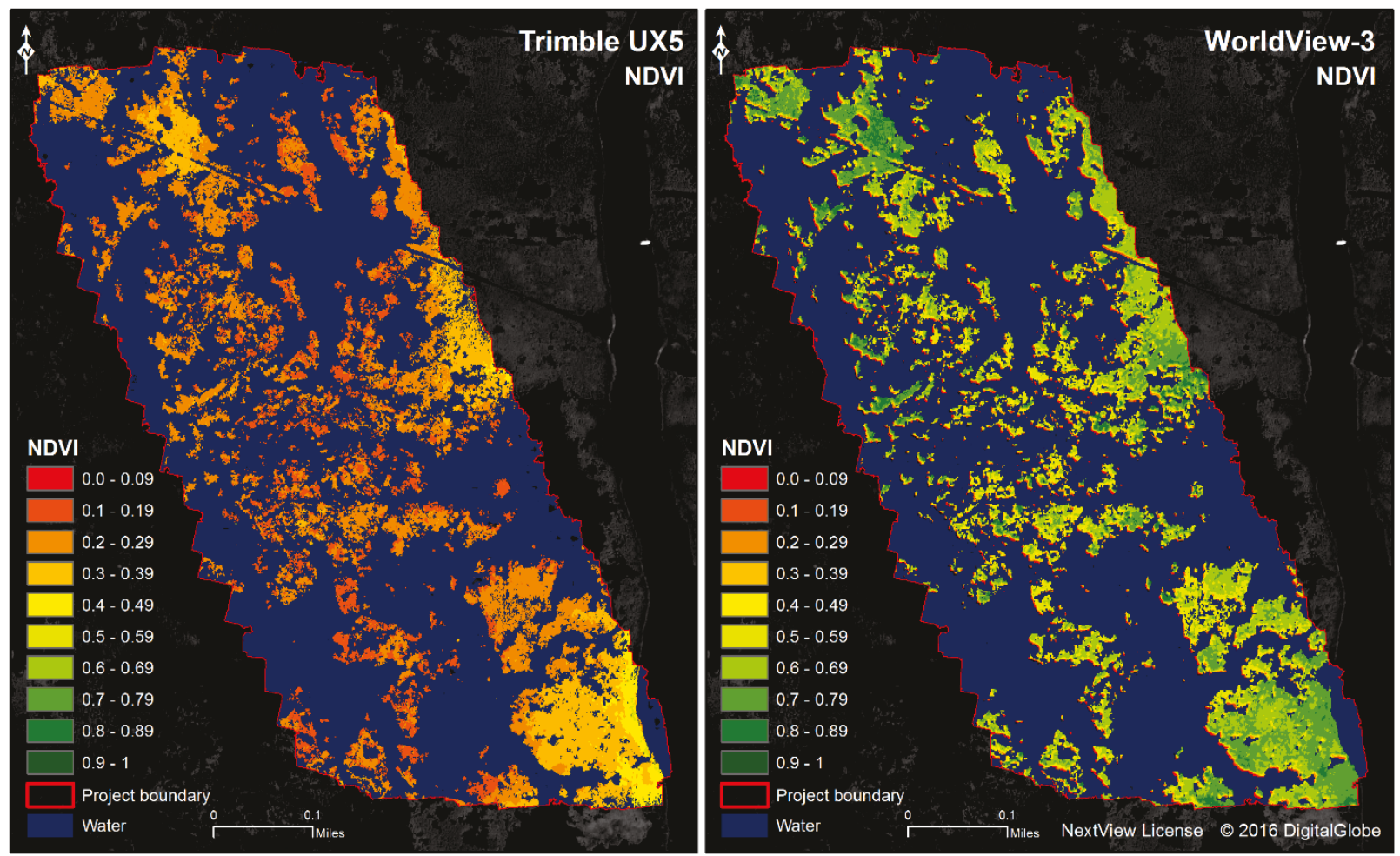

Figure 4. Normalized Difference Vegetation Index (NDVI) (UAS - left, and satellite - right). Imagery collected on 30 August 2016.

Table 1. Normalized Difference Vegetative Index (NDVI) error summary statistics for UAS and WorldView-derived data.

\begin{tabular}{|c|c|c|c|}
\hline Statistic & Value & Statistic & Value \\
\hline$n$ & 499 & MAE & 0.112 \\
\hline $\min$ & -0.324 & RMSE & 0.215 \\
\hline $\max$ & 0.803 & skewness & 1.234 \\
\hline mean difference & 0.086 & kurtosis & 0.723 \\
\hline std. dev. & 0.197 & NMAS (LE90) & 0.354 \\
\hline 3 sigma & 0.645 & NSSDA (LE95) & 0.421 \\
\hline mean difference squared & 0.046 & 95th percentile & 0.466 \\
\hline
\end{tabular}

Land-water assessments. Figure 5 shows the land-water data sets that were generated from the UAS (left panel) and WorldView (right panel) imagery. The UAS classification returned a landscape consisting of 20.8 ha and 51.7 ha for land and water, respectively. The WorldView classification returned a landscape consisting of 20.3 ha and 52.2 ha for land and water, respectively. Though these land and water totals are similar, confusion matrix in Table 2 shows that the agreement of classification was moderate $($ Kappa $=0.69)$. The water classes had a higher classification accuracy than the land classes. Classification accuracies of the UAS and WV land and water data were also calculated against the CRMS land and water data (derived from 2015 aerial photography, 1 meter). Table 3 compares the UAS land and water classification to the CRMS data, while Table 4 compares the WorldView and CRMS data. These tables show lower agreements with the CRMS data, with the UAS land and water data having higher agreement than the WordView data. 

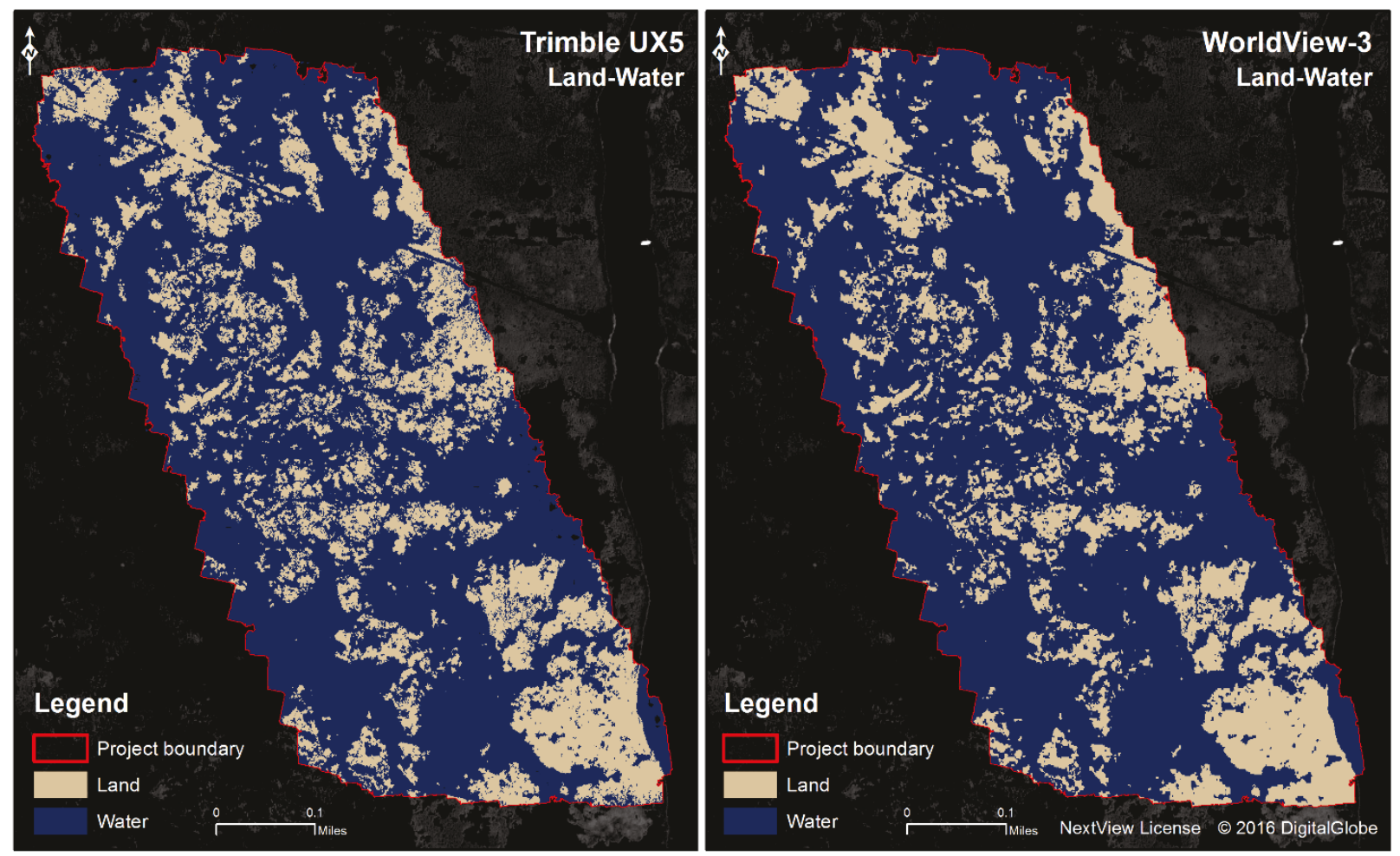

Figure 5. Land-water interface (UAS - left, and satellite - right). Imagery collected on 30 August 2016.

Table 2. Confusion matrix comparing land/water data derived from UAS and WorldView sensors.

\begin{tabular}{|l|rrrrr|}
\hline ClassValue & Land & Water & Total & U_Accuracy & Kappa \\
\hline Land & 110 & 33 & 143 & 0.77 & 0 \\
Water & 31 & 326 & 357 & 0.91 & 0 \\
Total & 141 & 359 & 500 & 0.00 & 0 \\
P_Accuracy & 0.78 & 0.91 & 0 & 0.87 & 0 \\
Kappa & 0 & 0 & 0 & 0 & 0.69 \\
\hline
\end{tabular}

Table 3. Confusion matrix comparing land/water data derived from UAS and CRMS.

\begin{tabular}{|l|rrrrr|}
\hline ClassValue & Land & Water & Total & U_Accuracy & Kappa \\
\hline Land & 101 & 76 & 177 & 0.571 & 0 \\
Water & 1 & 257 & 258 & 0.996 & 0 \\
Total & 102 & 333 & 435 & 0 & 0 \\
P_Accuracy & 0.990 & 0.772 & 0 & 0.823 & 0 \\
Kappa & 0 & 0 & 0 & 0 & 0.607 \\
\hline
\end{tabular}


Table 4. Confusion matrix comparing land/water data derived from WorldView and CRMS.

\begin{tabular}{|l|rrrrr|}
\hline ClassValue & Land & Water & Total & U_Accuracy & Kappa \\
\hline Land & 92 & 85 & 177 & 0.520 & 0 \\
Water & 6 & 252 & 258 & 0.977 & 0 \\
Total & 98 & 337 & 435 & 0 & 0 \\
P_Accuracy & 0.939 & 0.748 & 0 & 0.791 & 0 \\
Kappa & 0 & 0 & 0 & 0 & 0.534 \\
\hline
\end{tabular}

The hyperspatial resolution of the UAS data set allowed for the classification of smaller pockets and ponds of water as opposed to the slightly coarser satellite data. Thus, calculations of percent land or percent water are not comparable amongst the two methods. For this reason, any comparison of current conditions with traditional estimates (i.e., CRMS program) (CPRA 2012), it is recommended to use the satellite-based workflow presented here. This would ensure a similar pixel-based methodology but improve the estimation due to the slightly higher resolution of WV satellite data $(30-50 \mathrm{~cm})$ as opposed to the traditional $1 \mathrm{~m}$ aerial imagery, this is the basis of the CRMS analysis (CPRA 2012).

Species Classification Assessments. Figure 6 shows the dominant species classification that was performed using the UAS (left panel) and WV (right panel) imagery. The dominant species or primary habitat types are color coded, where Grass, Other, Reeds, and Water classes are represented by green, orange, red, and blue, respectively. The WorldView derived dominant species data show that the project area consisted of $0.10,1.9,18.79$, and 51.71 ha of Reed, Other, Grass, and Water classes, respectively. While the WorldView derived data consisted of $0.38,4.36,15.56$, and 52.2 ha of Reed, Other, Grass, and Water classes, respectively. Table 5 provides a measure of agreement between the two dominant species data sets. The confusion matrix show a moderate Kappa value of 0.55 , with the largest differences occurring in the Other class, followed by Reed and Grass classes. Overall, there was a high level of agreement in the Water classes from each data set. The areas of disagreement are potentially due to cloud shadows in the WV image, and the differences in image grain size. Interestingly, the footprint of the "Reed" class was consistent in both workflows. Only the extent of the Other class differed substantially between the workflows. This is possibly a result of the limited training data used in the supervised classification process on the satellite data or a lack of transferability of the greenness algorithms from the UAS OBIA to the satellite pixel-based classification. 

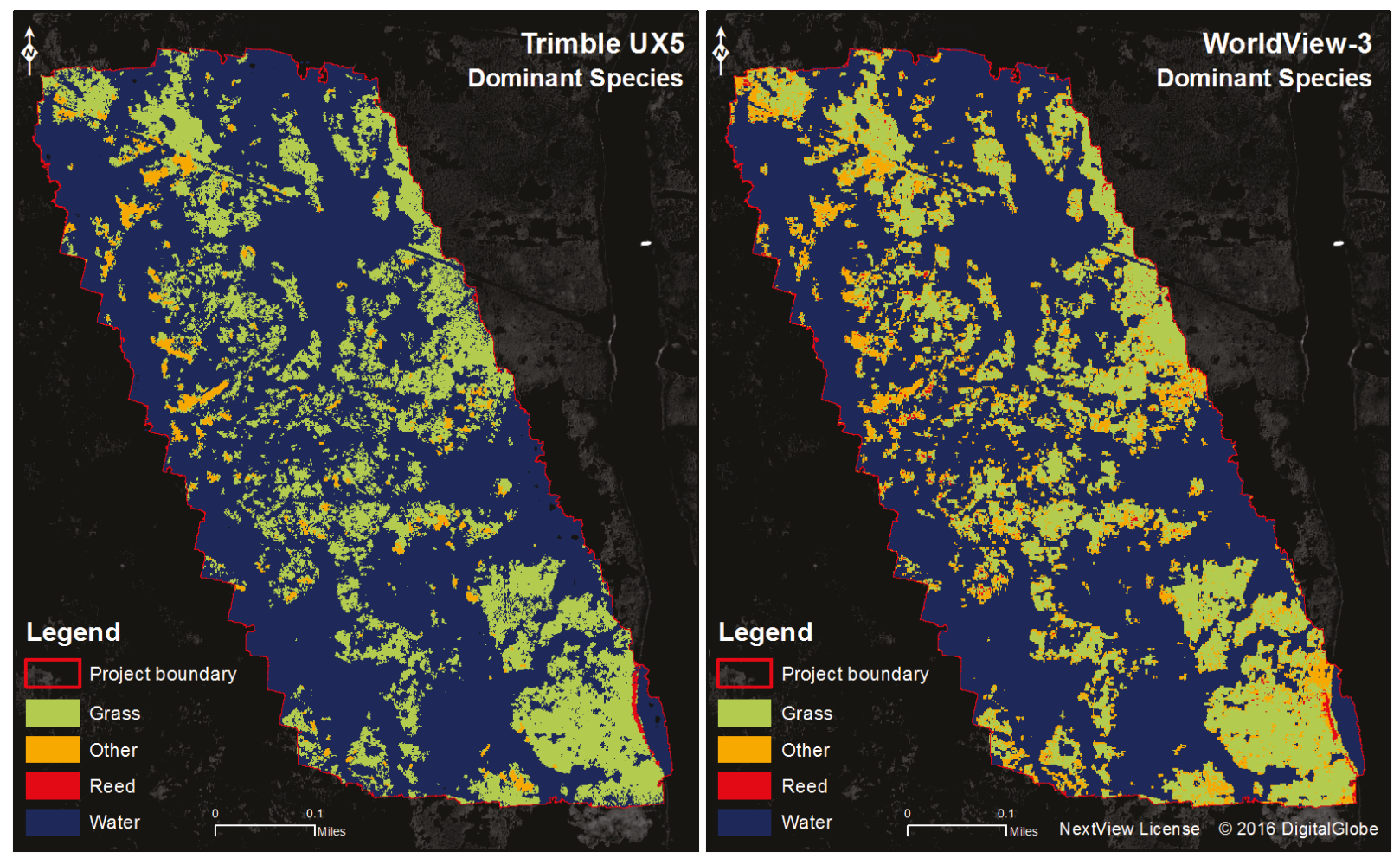

Figure 6. Dominant species classification (UAS - left, and satellite - right). Imagery collected on 30 August 2016

\section{Table 5. Confusion matrix comparing dominant species classes from UAS and WorldView sensors.}

\begin{tabular}{|l|rrrrrrr|}
\hline ClassValue & Reeds & Grass & Other & Water & Total & U_Accuracy & Kappa \\
\hline Reeds & 4 & 2 & 3 & 1 & 10 & 0.400 & 0 \\
Grass & 2 & 82 & 31 & 15 & 130 & 0.631 & 0 \\
Other & 0 & 5 & 8 & 0 & 13 & 0.615 & 0 \\
Water & 0 & 32 & 24 & 300 & 356 & 0.843 & 0 \\
Total & 6 & 121 & 66 & 316 & 509 & 0 & 0 \\
P_Accuracy & 0.667 & 0.678 & 0.121 & 0.949 & 0 & 0.774 & 0 \\
Kappa & 0 & 0 & 0 & 0 & 0 & 0 & $\mathbf{0 . 5 5 0}$ \\
\hline
\end{tabular}

Elevation assessments. Photogrammetrically-derived digital surface models benefit from multiple perspectives and are well suited for UAS workflows because a singular point can be captured in as many as ten overlapping UAS images. This scenario can produce fairly accurate $(4.74 \mathrm{~cm}, 95 \%$ vertical confidence) elevation predictions (Figure 7). Stereo-pairs of WorldView imagery can also produce elevation estimates using photogrammetric techniques (Figure 7). The WorldView assessment also utilized existing LiDAR data (2015) to assist with accuracy assessments of the DSM data. The mean surface elevations were $0.79,0.38$, and $0.298 \mathrm{~m}$, for the UAS, WV, and LiDAR data, respectively. Table 6 provides summary statistics describing the difference between in UAS and WV elevation values at coincident points. The MAE and RMSE between the UAS and WV elevation data sets are 0.196 and 0.419 , respectively (Table 6). Overall, it appears that 
smoothing techniques were used to generate the DSM data from UAS imagery, and no filtering was applied upon the satellite-derived DSM data. The limited number of photos, ground sample distance, and absolute accuracy of the raw imagery constrains the final accuracy of the satellite-based DSMs. For coarse-scaled, regional assessments, the technique presented here is reasonable and economical.
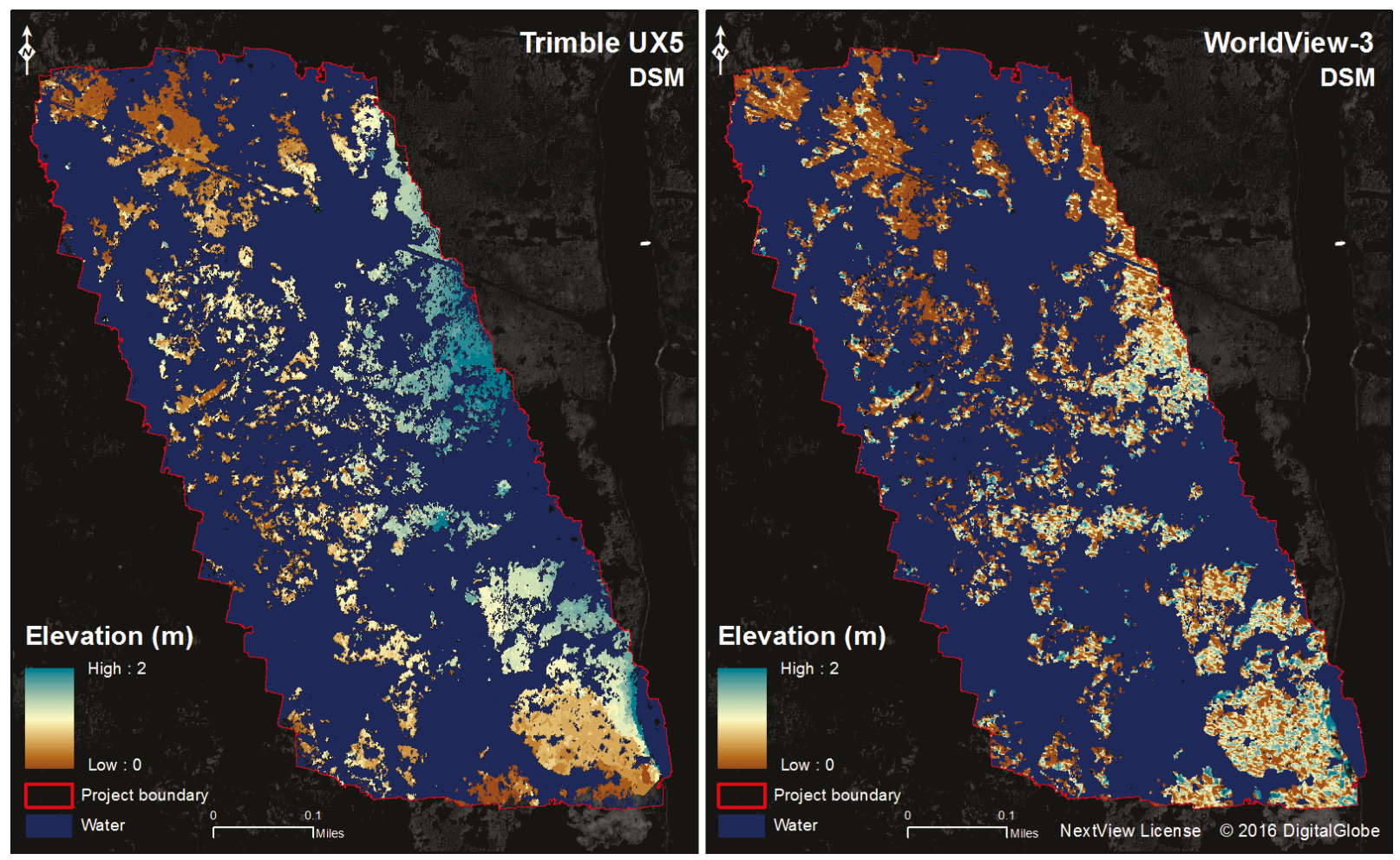

Figure 7. Photogrammetrically-derived Digital Surface Models (UAS - left, and satellite - right). UAS imagery collected on 30 August 2016 and satellite imagery collected on 21 October 2016.

Table 6. Digital Surface Model error summary statistics for UAS and WorldView-derived elevation data.

\begin{tabular}{|c|c|c|c|}
\hline Statistic & Value & Statistic & Value \\
\hline $\mathbf{n}$ & 498 & MAE & 0.196 \\
\hline $\min$ & -0.877 & RMSE & 0.419 \\
\hline $\max$ & 1.650 & skewness & 1.697 \\
\hline mean difference & 0.173 & kurtosis & 2.338 \\
\hline std. dev. & 0.382 & NMAS (LE90) & 0.689 \\
\hline 3 sigma & 1.256 & NSSDA (LE95) & 0.821 \\
\hline mean difference squared & 0.175 & 95th percentile & 1.076 \\
\hline
\end{tabular}

Landscape metric assessments. Landscape metrics were used to generate and compare standard measures of wetland structure derived from air- and space-borne data. Table 7 provides a summary of the metrics and values that were generated for this assessment. The area based metrics show similarities in the amount and proportion of land and water classes in the project area, while the patch 
and density metrics show large differences. These are related to the grain size of the imagery, where higher accuracy is expected with increasing spatial resolution data. Moderate differences were observed in the Aggregation Index, where higher accuracy is expected with higher spatial resolution data. Though these metrics can be useful for comparing target landscapes to reference landscapes, the utility of these measures are generally found in the ability to track their changes through space and time, and linking those structural changes to ecosystem stressors and function.

\section{Table 7. Landscape metrics (class level statistics) computed from the UAS and WorldView-derived land and water classified data.}

\begin{tabular}{llcrrrrr}
\hline LID & TYPE & $\begin{array}{c}\text { Total } \\
\text { Class }\end{array}$ & $\begin{array}{c}\text { Prea } \\
\text { of Landscape }\end{array}$ & $\begin{array}{c}\text { Number of } \\
\text { Patches }\end{array}$ & \multicolumn{1}{c}{$\begin{array}{c}\text { Patch } \\
\text { Density }\end{array}$} & $\begin{array}{c}\text { Edge } \\
\text { Density }\end{array}$ & $\begin{array}{c}\text { Aggregation } \\
\text { Index }\end{array}$ \\
\hline UAS & land & 20.7689 & 28.6598 & 1203 & 1660.0637 & 1501.509 & 86.8966 \\
UAS & water & 51.6982 & 71.3402 & 1561 & 2154.081 & 1501.509 & 94.6026 \\
WorldView & land & 20.2972 & 27.9835 & 853 & 1176.0213 & 906.212 & 91.8641 \\
WorldView & water & 52.2355 & 72.0165 & 522 & 719.6754 & 906.212 & 96.7834 \\
\hline
\end{tabular}

CONCLUSION: UAS and satellite-based operations in the coastal environment are filling important niches for site-specific, landscape, and regional monitoring of restoration activities. A defining advantage of remote sensing workflows and applications is the ability to "scale up" ground measurements and assess the conditions of larger landscapes. It is the specific needs of a project, including its scope, time, and budget constraints, that determines the most appropriate method and data source. The areal extent of satellite imagery makes it well suited for regional assessments of large areas. With rapidly increasing spatial and temporal resolution, satellite sensors are beginning to offer data sets that rival traditional aerial photography. This combination is highly advantageous for large projects.

The goal of this study was to demonstrate photogrammetric methods and evaluate and compare UAS and high-resolution satellite-derived products for wetland monitoring. Through these comparisons, the benefits of the higher spatial resolution UAS data are realized with the vegetation and land/water classifications. The hyperspatial imagery and object based classification methods allow for more accurate determination of dominant vegetation communities and the ability to detect and categorize smaller (i.e., sub-meter) wetland features. However, the results from the satellite-derived products were largely similar to those from the UAS. For some products and applications, especially those projects requiring a large area of interest, the cost (e.g., time and money) of the UAS approach (collection/processing) may not outweigh the benefits that are experienced over the space-borne methods. This was observed with the NDVI and elevation data, which aside from lacking the spatial resolution necessary to identify the smallest land and water features, has more established and efficient methods for performing some remote sensing techniques on regional and landscape scales.

UASs, and to some respect the higher spatial, spectral, and temporal resolution satellites, overcome many of the limitations (i.e., access, frequency, cloud cover) that are experienced with more traditional in situ and moderate resolution data collections. The trade-offs between these options are that the higher resolution data require CPU-intensive post-processing techniques and may require additional validation. 
This study demonstrated the utility and applicability of these novel systems and data, but it may be that a combination of these approaches (traditional photography, UAS, and space-borne data) are necessary to provide adequate coverage and metrics to fulfill monitoring, management, and regulatory needs. Future work should expand upon this study to evaluate other UAS mounted sensors (i.e., LiDAR, multispectral, and hyperspectral) to assess wetland structure and function metrics across a wider range of ecosystem landscapes.

ACKNOWLEDGMENTS: The authors gratefully acknowledge Mr. Robert Brooks at The Pennsylvania State University, Mr. Tom Cousté at JESCO Environmental and Geotechnical Services, Inc., and Mrs. Sally Stroupe, Manager of the Wetlands Regulatory Assistance Program, for their support on this project. Comments provided by Mr. Shea Hammond and Ms. Christina Saltus contributed to the clarity and quality of this report.

POINTS OF CONTACT: This technical note was written by Dr. Whitney P. Broussard III, JESCO Environmental and Geotechnical Services, Inc., and Dr. Glenn M. Suir, Environmental Laboratory (EL), Engineer Research and Development Center (ERDC). For additional information, contact Whitney Broussard (337) 824-9074, wbroussard@jescous.com or Dr. Glenn M. Suir (225) 578-7417, Glenn.M.Suir@usace.army.mil. This technical note should be cited as follows:

Broussard III, W. P., G. M. Suir, and J. M. Visser. 2018. UAS and satellite imagery collections in a coastal intermediate marsh to determine the land-water interface, vegetation types, and NDVI values. ERDC/TN WRAP-18-1. Vicksburg, MS: U.S. Army Engineer Research and Development Center.

\section{REFERENCES}

An, N., K. P. Price, and J. M. Blair. 2013. Estimating above-ground net primary productivity of the tallgrass prairie ecosystem of the central great plains using AVHRR NDVI. International Journal of Remote Sensing 34(11): 3717-3735.

Anderson, K. and K. J. Gaston. 2013. Lightweight unmanned aerial vehicles will revolutionize spatial ecology. Frontiers in Ecology and the Environment 11(3): 138-146.

Bianchette, T. A., K. B. Liu, N. N. Lam, and L. M. Kiage. 2009. Ecological impacts of Hurricane Ivan on the Gulf Coast of Alabama: A remote sensing study. Journal of Coastal Research 56:1622-1626.

Carle, M. 2013. Spatial structure and dynamics of the plant communities in a pro-grading river delta: Wax Lake Delta, Atchafalaya Bay, Louisiana. Baton Rouge, LA: Louisiana State University Doctoral Dissertation.

Chabreck, R. H. and G. Linscombe. 1978. Vegetative type map of the Louisiana coastal marshes. Baton Rouge, Louisiana: Louisiana Department of Wildlife and Fisheries.

Chamberlain, S. J. and H. M. Ingram. 2012. Developing coefficients of conservatism to advance floristic quality assessment in the Mid-Atlantic region1. The Journal of the Torrey Botanical Society 139(4): 416-427.

Coastal Protection and Restoration Authority of Louisiana (CPRA). 2012. CRMS0392 2012 Land-water analysis. Coastal Protection and Restoration Authority. Data set https://www.lacoast.gov/crms2/ crmsProducts.aspx? PRODTYPE $=e L W$

Couvillion, B. R., M. R. Fischer, H. J. Beck, and W. J. Sleavin. 2016. Spatial configuration trends in coastal Louisiana from 1985 to 2010 Wetlands 36(2): 347-359. 
Couvillion, B. R. and H. J. Beck. 2013. Marsh collapse thresholds for coastal Louisiana estimated using elevation and vegetation index data. Journal of Coastal Research 63: 58-67.

Cretini, K. F., J. M. Visser, K. W. Krauss, and G. D. Steyer. 2012. Development and use of a floristic quality index for coastal Louisiana marshes. Environmental monitoring and assessment 184(4): 2389-2403.

Eisenbeiss, H., K. Lambers, and M. Sauerbier. 2005. Photogrammetric recording of the archaeological site of Pinchango Alto (Palpa, Peru) using a mini helicopter (UAV). Annual Conference on Computer Applications and Quantitative Methods in Archaeology CAA March 2005:21-24.

Folse, T. M., L. A. Sharp, J. L. West, M. K. Hymel, J. P. Troutman, T. McGinnis, D. Weifenbach, W. M. Boshart, L. B. Rodrigue, D. C. Richardi, W. B. Wood, and C. M. Miller. 2014. A standard operating procedures manual for the coast-wide reference monitoring system-wetlands: Methods for site establishment, data collection, and quality assurance/quality control. Baton Rouge, LA: Louisiana Coastal Protection and Restoration Authority, Office of Coastal Protection and Restoration.

Gustafson, E. J. 1998. Quantifying landscape spatial pattern: what is the state of the art? Ecosystems 1(2): $143-156$.

He, H. S., B. E. DeZonia, and D. J. Mladenoff. 2000. An aggregation index (AI) to quantify spatial patterns of landscapes. Landscape Ecology, 15(7): 591-601.

ITT Visual Information Solutions Inc. 2009. ENVI atmospheric correction module: QUAC and FLAASH user's guide v. 4.7. Boulder, CO: ITT Visual Information Solutions Inc. http://www.harrisgeospatial.com/portals/0/pdfs/envi/Flaash_Module.pdf.

Klemas, V. 2013. Remote sensing of coastal wetland biomass: An overview. Journal of Coastal Research 29(5): 1016-1028.

Laliberte, A. S., and A. Rango. 2009. Texture and scale in object-based analysis of subdecimeter resolution unmanned aerial vehicle (UAV) imagery. IEEE Transactions on Geoscience and Remote Sensing 47(3): 1-10. doi:10.1109/TGRS.2008.2009355.

Laliberte, A. S., and A. Rango. 2011. Image processing and classification procedures for analysis of subdecimeter imagery acquired with an unmanned aircraft over arid rangelands. GIScience and Remote Sensing 48(1): 4-23. doi:10.2747/1548-1603.48.1.4.

Lechner, A. M., A. Fletcher, K. Johansen, P. Erskine. 2012. Characterizing upland swamps using objectbased classification methods and hyper-spatial resolution imagery derived from an unmanned aerial vehicle. In ISPRS Annals of Photogrammetry, Remote Sensing and Spatial Information Sciences I-4 (September): 101-6. doi:10.5194/isprsannals-I-4-101-2012.

Liu, A. J., and G. N. Cameron. 2001. Analysis of landscape patterns in coastal wetlands of Galveston Bay, Texas (USA). Landscape Ecology 16:581-595.

Luo, S., C. Wang, F. Pan, X. Xi, G. Li, S. Nie, and S. Xia. 2015. Estimation of wetland vegetation height and leaf area index using airborne laser scanning data. Ecological Indicators 48: 550-559.

Maglione, P., C. Parente, and A. Vallario. 2016. Pan-sharpening Worldview-2: IHS, Brovey and Zhang methods in comparison. International Journal of Engineering Technology 8(2): 673-679.

McGarigal, K. 2015 FRAGSTATS help. Pieejams: https://www.umass.edu/landeco/research/fragstats/documents/fragstats.help.4.2.pdf.

O’Neil, T. 1949. The muskrat in Louisiana coastal marshes. New Orleans, Louisiana: Louisiana Department of Wildlife and Fisheries. 
Pereira, E., R. Beneatel, J. Correia, L. Felix, G. Goncalves, J. Morgado, and J. Sousa. 2009. Unmanned air vehicles for coastal and environmental research. In Proceedings of the 10th International Coastal Symposium ICS 2009, Vol. II Journal of Coastal Research 56: 1557-61.

Przybilla, H. J., and W. Wester-Ebbinghaus. 1979. Bildflug mit ferngelenktem kleinflug- zeug. bildmessung und luftbildwesen zeitschrift fuer photogrammetrie ferner. Kundung 47(5): 137-142.

Reif, M. K., C. L. Macon, and J. M. Wozencraft. 2011. Post-Katrina land-cover, elevation, and volume change assessment along the south shore of Lake Pontchartrain, Louisiana, U.S.A. Journal of Coastal Research 10062: 30-39.

Rouse, J. W., R. H. Haas, J. A. Scell, D. W. Deering, and J. C. Harlan. 1974. Monitoring the vernal advancement of retrogradiation of natural vegetation. Washington, DC: National Aeronautical and Space Administration (NASA)/GSFC Type III, 371.

Sasser, C. E., J. M. Visser, E. Mouton, J. Linscombe, and S. B. Hartley. 2014 Vegetation types in coastal Louisiana in 2013: U.S. Geological Survey scientific investigations map 3290, 1 sheet, scale 1:550,000.

Steyer, G. D. 2010. Coastwide reference monitoring system (CRMS): U.S. Geological Survey Fact Sheet 2010-3018. http://lacoast.gov/crms2/home.aspx.

Steyer, G. D., B. R. Couvillion, and J. A. Barras. 2013. Monitoring vegetation response to episodic disturbance events by using multitemporal vegetation indices. Journal of Coastal Research 63(sp1): 118-130.

Suir, G. M., D. E. Evers, G. D. Steyer, and C. E. Sasser. 2013. Development of a reproducible method for determining quantity of water and its configuration in a marsh landscape. Journal of Coastal Research 63(sp1): 110-117.

Tucker, C. J. 1979. Red and photographic infrared linear combinations for monitoring vegetation. Remote Sensing of Environment 8(2): 127-50. doi:10.1016/0034-4257(79)90013-0.

U.S. Geological Survey (USGS). 2016. LiDAR Acquisition 02/13/2015 Terrebonne, LA - QL2. Denver, CO: United States Geological Survey.

U.S. Geological Survey (USGS) and LA Coastal Protection and Restoration Authority (LACPRA). 2018. Coastal reference monitoring system. www.lacoast.gov/crms.

Visual Information Solutions (ENVI). 2009. DEM extraction module user's guide version 4.7. Broomfield, CO: Harris Geospatial, ITT Visual Information Solutions.

http://www.harrisgeospatial.com/portals/0/pdfs/

envi/DEM_Extraction_Module.pdf.

Whitehead, K. and C. H. Hugenholtz. 2014. Remote sensing of the environment with small unmanned aircraft systems (UASs), part 1: A review of progress and challenges 1. Journal of Unmanned Vehicle Systems 2(3):69-85.

Wolf, A. F. 2010. Using WorldView 2 Vis-NIR MSI imagery to support land mapping and feature extraction using normalized difference index ratios. In Proceedings SPIE Volume 8390 - SPIE Defense, Security, and Sensing|. https://doi.org/10.1117/12.917717.

NOTE: The contents of this technical note are not to be used for advertising, publication, or promotional purposes. Citation of trade names does not constitute an official endorsement or approval of the use of such products. 